and several anthors recognised that the best hope lay in immediate destruction of the wound either by complete excision or by the application of some strong destructive. Thus, Dr. Johnstone says : "I apprehend the surest preventive is to cut away or scarify the bitten part immediately, and to destroy it by caustic or actual cautery." Mercury or antimony were applied to the wound, and, if they did any good, no doubt acted as antiseptics. Dr. White, of St. Edmundsbury, in 1792 stated that his part of the country had been terribly infested with mad dogs. He records that a foal was bitten on the nostril by a mad dog. He excised the wound and five months after the animal was quite well, although a horse, a cow, and two pigs bitten by the same dog on the same day had all died. They were treated by internal remedies; excision was not attempted. He records ten cases in human beings, in all of whom the bitten part was wholly removed. Thus, in one case the bitten finger was amputated. He is "in hopes from the interval that has elapsed that they are freed from danger." "Two persons on whom excision and ablution had not been performed, and to whom medicines of false repute had been given, fell victims to their credulity." He considers that the virus may be exter minated by excision many days after the injury. Dr. Dexter says the following plan is found in New England to be most successful: "Immediately after the accident the part is well washed in warm water saturated with common salt, then scarified and cupped, and 1 to 2 drachms of strong mercurial is rubbed into the wound and the adjacent parts this is continued for 25 or 30 days if signs of mercurial poisoning do not supervene.

The perusal of all these papers leaves the reader with a strong impression that excision of the wounded parts or their destruction was the most approved treatment. The earlier this was done the better, and a case is given in which death ensued, although excision was performed and caustic was applied four days after the bite; nevertheless, the opinion was that it was always worth while trying this plan any time after the bite before the symptoms of hydrophobia appeared, for, as is well known, this may not be until many months later. In one of the cases here recorded it was nine months. You will, I know, agree with me that, considering the state of knowledge then, most hope lay in excision or destruction of the wound and strong antiseptics, as advocated by the majority of writers at the time. Giving an oil bath, or inunction with or drinking oil was advised by a few. Domestic animals-e.g., horses, cows, and pigs-were frequently afflicted with the disease after being bitten by a mad dog. Dr. Shadwell says he was told that a pig thus affected leapt 12 feet in the air, but he does not believe this.

Tetanus, Influenza, Typhus.

Tetanus occupies a considerable space in the first five volumes of our Memoirs. Excision of the wound before the symptoms appeared was not practised, because, unlike hydrophobia, there was nothing in the mode of infliction to show that tetanus is likely to follow. The disease could only be treated after its appearance, and the treatment was as good as could be adopted, its object being to relieve the spasms. Hence enormous quantities of opium were given.

For example, one sufferer had $2 \mathrm{gr}$. of opium every hour and later $5 \frac{1}{2} \mathrm{fl}$. oz. of landanum in 26 hours. Alcohol was given for the same purpose; thus, a man who got well had from 60 to 120 drops of tincture of opium every night, and he also had 110 bottles of port in 42 days. In spite of this quantity he never had "any symptom of ebriety; it soothed the irritation of his nerves and comforted his mind, and without increasing the frequency of his pulse it angmented his strength." James Currie and others advised the cold bath. A man suffering from traumatic tetanus was thrown into the public salt-water bath at Liverpool, the temperature of which was $36^{\circ} \mathrm{F}$. The good effects in this case were instantaneous. These baths were repeated for 14 days and the patient got quite well. Other cases treated in the same way are recorded, and we find that a horse was treated by being thrown into a river, and another by having cold water poured over him. But as our present experience would lead us to expect, treatment usually failed.

Influenza came in epidemics, and was the cause of much illness.

Dr. Fothergill states that in November, 1775, "it began to make its appearance at Northampton, and soon became more general than any other epidemic within my remembrance." Horses suffered; it ran through whole packs of hounds. He was quite unable to explain its coming. Another epidemic occurred in 1782. Altogether in that century there were epidemics in 1709, 1733, 1743, 1762, 1767, 1775, and 1782 From the descriptions given the symptoms were much the same as we know; perhaps sore-throat and cough were even more common; cough was very constant and very severe. Collective investigation is by no means new. Such was the seriousness of influenza that in 1803 this Society sent a list of 32 questions about influenza to each of its corresponding members. Fifty-eight answered, and their replies occupy more than 300 pages of our Memoirs. The Government attached so much value to this investigation that they franked all the replies.

Typhus was then common. Jenner had it. Lettsom was called to see Lord George Gordon in Newgate on Oct. 25th 1793. He died from typhus. Other prisoners died and the doctor to the prison caught it. Lettsom, in a paper on Newgate prison, gives excellent advice as to the best way of preventing typhus in gaols.

The reading of these ancient volumes was undertaken in order that by actual extracts from them I might carry you back to the time at which the societies were founded. If I have succeeded and you have reached the same conclusion as myself it will appear to you that in actual knowledge we are far in front of our forefathers who lived 120 or more years ago, but that in enthusiasm for learning all that lies in our power to know about medicine and surgery, in scientific attitnde of mind, in careful observation, in wisdom and in sound judgment, they were fully as capable as, we are, and that if we, present members of the Medical Society, use our much greater knowledge as well as our earliest members used theirs, we shall be doing well.

\section{EXTRAPLEURAL THORACOPLASTY IN THE TREATMENT OF PULMONARY TUBERCULOSIS,}

WITH AN ACCOUNT OF 37 CASES.

BY P. BULL, M.D.

PROFESSOR OF SORGERY, ROYAL CNIVERSTTY, CHRISTIANIA,

THE theory underlying the operative treatment of tuberculosis of the lungs is in close connexion with the conception that certain mechanical factors facilitate the development of pulmonary tuberculosis or present obstacles to its cure. It is now almost two generations since W. A. Freund put forward his well-known hypothesis in explanation of the predisposition of the apex of the lungs to tuberculosis.

He considered that the cause was to be found in the rigidity of the first rib, which to some extent constricts the apex of the lung. As in addition the first costal cartilage is often found to be calcified in cases of pulmonary tuberculosis, the range of movement of the cases of pulmonary tuberculosis, the range of movement of the opinion both these factors occasion reduced mobility of the apex of the lungs, and thereby diminished activity in this region. Following this hypothesis a resection of the cartilage of the first rib in cases of apical tuberculosis was at one time suggested. This procases of however, has rarely been put into practice. The object of posal, however, has ravely been put into practice. The object of such an operation must either be prophylactic or curative in early cases of puimonary tuberculosis. In the former case it would be impossible to lay down serviceable indications for the operation, and the latter class consists of patients who orten recover withou operation, operative treatment, therefore, not being indicated. An additional argument against this operation is that its essential object, the production of greater mobility in the apices of the lungs,
conflicts with the generally accepted principle for the treatment of conflicts with the generally accept

tuberculosis by immobilisation.
There was a better foundation for the proposal, put forward by There was a better foundation for the proposal, put forward by
Quincke in 1888 , to remove the rib covering a cavity in the lung $H$. Quincke in 1888, to remove the rib covering a cavity in the lung,
for Quincke started from the correct supposition that it is for Quincke started from the correct supposition that it is mainly the rigid chest wall that prevents the walls of a cavity
from collapsing on the contraction of the fibrous tissue formed in from collapsing on the contraction of the fibrous tissue formed in the lung. Quincke's proposal did not meet with the support one
might have expected for it; C. Spengler alone took up the idea, might have expected for it; C. Spengler alone took up the idea,
but he employed the method solely in cases with coincident but he employed the method solely in cases with coincident
pleural exudation. It was not until 1903 that he performed the operation to which he gave the name extrapleural thoracoplasty. $K$. Turban may be said to have been the fixst to remove any considerable section of ribs in unilateral pulmonary tuberculosis. In 1899 he removed $64.5 \mathrm{~cm}$. of ribs from the fourth to the tenth, In 1902 Landerer published no less than nine similar cases. However, the operation did not win other advocates as the results were not good. It was not until experiences of pneumothorax treatment had shown that it was not only essential to get the lung partially collapsed, but that it must be put completely out of action, that in 1907 it occurred to $\mathbf{L}$. Brauer, at that time professor of medicine at Marburg, that a large part of the ribs must be removed if both the above objects were to be achieved. In December of the same year, on Brauer's initiative, P. L. Friedrich performed his first great thoracoplasty, employing M. Schede's large arc-shaped incision for old empyema. At first Friedrich aimed at removing the inter-
costal muscles and periosteum as well as the bone, but this 
technique increased the difficulties of the operation so much that it was subsequently abandoned. Friedrich's operation forms the starting-point for a numerous series of operations since performed, chiefy by Friedrich, Brauer, and particularly F. Sauerbruch; also by Wilms.

The improvements that have taken place during the last few years consist mainly in the alteration of the site of resection to the posterior part of the ribs, and in the employment of local anæsthetics instead of narcosis.

At the Congress of Northern Surgeons at Gothenburg, 1916, I read a paper on my first 11 cases of thoracoplasty for pulmonary tuberculosis, the first operation having been performed in May, 1914. On the same occasion Dr. E. Key, of Stockholin, reported 7 cases and Dr. Christensen, of Christiania, 4 cases. At the Congress of Northern Surgeons at Christiania, July, 1919, the following references were made to operations performed: Dr. Key, 34 cases (4 dead); Professor C. Saugman, director of Vejlefjord Sanatorium, Denmark, 41 cases (4 dead); Dr. Christensen, 13 cases (0 dead); and I myself, 37 cases (4 dead). In the last year I have carried out 11 new operations, making 48 in all; but as I cannot yet know the ultimate fate of these last patients I will here discuss the first 37 only, in whom the operation was performed from one to six operated 24 times on the left side, 13 times on the right, left and right in equal numbers in the men, and 18 left, 7 right in the women.

\section{Technique: Introductory Remarks.}

The object of extrapleural thoracoplasty is to produce collapse of the lung. Of the various methods employed for that purpose, the best is that which combines the lexst risk to the patient's life and future capacity for work, with the greatest likelihood of a sufficient falling-in of the wall of the chest and resultant retraction of the lung tissue, at the same time putting the lung more or less out of action. Those surgeons who have specially occupied themselves with this branch of surgery-viz., Friedrich, Brauer, Sauerbruch, and Wilms - have more and more closely approached each other's methods, and apart from the question of priority there is now a practical unanimity in the main features of the method, the greatest stress being laid upon the removal of the posterior section of the rib. This idea constantly appears in the "eighties" and "nineties" during the development of suitable methods of operating for old empyemata. It was A. Boiffin who in the middle " nineties" first clearly demonstrated, through J. Gourdet, a pupil, precisely why it is the posterior portion of the rib that must be removed. Gourdet's argument is as follows:-

On account of the yielding rib cartilage the anterior part of a rib can be pressed inwards, whilst the posterior portion is stiff and, practically speaking, immovably connected with vertebral column, and in any case can only be moved up and down a little. Further, the postexior part of a rib exhibits a marked concavity forwards, or, in other words, forms an are the radius of which is much less than that of the are of the rib otherwise; the angle of the rib forms the most prominent point in this are behind. Any resection of the ribs which is situated in front of the angle of the scapula leaves behind a stiff unvielding piece of rib, which in accordance with its length will prevent the soft parts from falling in and diminish the costo-vertebral angle. If on the other hand, we remove the posterior stiff part of the ribs the anterior part can very easily be turned about the costal cartilage and pressed in towards the thoraeic cavity and backwards towards the posterior fragment of rib, so that the entire arc of the rib decreases considerably in its curve and thereby also decreases the vecreases considerably in its curve and thereby also decreases the volume of the thorax. By this method the anterior part of the ribs is not hindered in its movements by the sort parts, which in other
methods stretch over the projecting posterior end of the rib. This methods stretch over the projecting posterior end of the rib. This principle, as set forth by Boiffin-Grourdet, runs through both

From Gourdet's book I have taken some drawings which illustrate these conditions in the various methods of operation. (See Figs. 1, 2, 3, 4.)

Which ribs, and how much of each rib, should be resected in order to be sure of obtaining the necessary effect?

Before replying to this question it is essential to form a clear idea of the fact that the objects of extrapleural thoracoplasty lie in two directions, which, however, converge. One object is to produce collapse of the lung, the other is to put it out of function, the latter being in conformity with the general rule for the treatment of tuberculosis of bones and joints. But just as in the treatment of coxitis we do not hesitate to place a healthy knee into a plaster bandage, so also in thoracoplasty we may also is diseased, to extend bes, even though only a portion of the lung prevent or at least considerably to reduce the respiratory excursions of the lung. The latter are dependent not only upon the movements of the thorax, but also upon those of the diaphrage movedecision to go so far down, however, depends upon whether the diaphragm is immobilised and drawn up beforehand on account of extensive adhesions between the lung and the wall of the thorax on the one side and the lung and the diaphragm on the other. This condition can be ascertained by means of the Rontgen rays. For the depression of the wall of the thorax the resection of the eleventh rib would scarcely be of importance; but in addition to contributing towards the immobilisation of the diaphragm it will possibly also facilitate its retraction upwards in the thoracic cavity, when the lung tissue shrinks during healing. On the other hand, the tenth rib should always be resected even though the affection of the linng is restricted to the upper lohe; but the length of the piece resected will depend, both as regards the tenth and ninth ribs, unon whether the lower lobe is infected. As far as the following ribs are concerned, I do not believe from what has already been stated with respect to the effect of resection of the posterior portion of the ribs, that it is necessary to resort to the extremely large resections that I made in several of my first cases. For that half of the thorax in which the diseased lung is found is far from empty, and even when the lung shrinks it will occups a certain amount of space. It is therefore not necessary to aim at a complete deossification of the thoracic wall and obliteration of one half of the thoracic cavity, but a restriction of its lumen, so that the sunken thorax wall close about the sunken lung, is sufficient. I believe that we can rely with tolerable certainty upon achieving this by resecting abou $12 \mathrm{~cm}$. of the tenth and ninth ribs and $15 \mathrm{~cm}$. of the succeeding ribs up to the fourth. But of course due regard must be taken to individual cases. When there is pronounced disease in the upper lobe we must at all costs resect the second and first ribs. One need only look at a skeleton to see how prominent the second rib is in relation to the first, and therefore how requisite it is to have it resected. I further consider that as regards the fourth, third, and second ribs we should not confine ourselves to removin $5-6 \mathrm{~cm}$. as is generally recommended, but even $12-13 \mathrm{~cm} .$, and in any case at least $10 \mathrm{~cm}$. The anteriol part of the uppermost rib after resection is not as movable as that of the lower ones, as the rib cartilage is shorter and stiffer and to some degree the seat of calcareous deposits in pulmonary tuberculosis; therefore the anterior ends cannot so easily be pressed back as those farther down, and for that reason we must remove relatively more of those ribs in order to obtain a depression in that region.
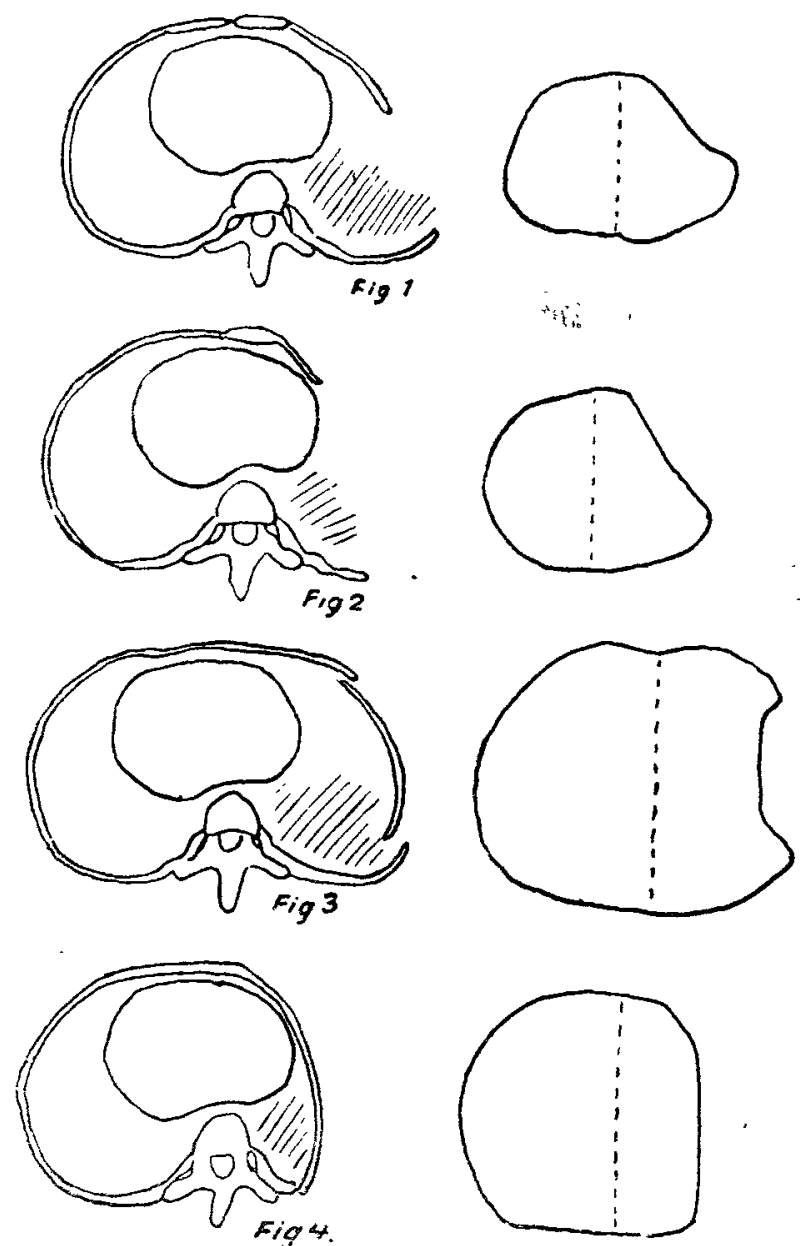

FIG. 1 shows the result of Estlander's operation from a cadaver after resection of five ribs. Elfect: Reduction of the circumference of the chest by $4 \mathrm{~cm}$.

FIG. 2, also Estlander's operation upon cadaver, but larger resections than Fig. 1, eight ribs being removed, giving a total of $110 \mathrm{~cm}$. Effect: Reduction of circumference by $5.5 \mathrm{~cm}$.

FIG. 3. Result of E. Quénu's operation, Resection before and behind of a small piece from each of seven ribs. Reduction of circumference $3 \mathrm{~cm}$.

FIG. 4. Boiffin-Gourdet's operation on cadaver. Resection of $6 \mathrm{~cm}$ of nine ribs, in all $54 \mathrm{~cm}$. Effect: $8 \mathrm{~cm}$. reduction of circumference of thorax. One sees how the front end of the resected ribs can be drawn backwards to make contact with the posterior end. The costo-vertebral angle has been almost obliterated.

The scapula is to a large extent the cause of our having to resect the upper ribs also in affections of the lower lobe.

It might perhaps be beliered that in an affection of the lower lobe it would be sufficient to resect the lower ribs up to the fourth. But apart from the consideration of the complete immobilisation of the lung, the scapula hinders the success of such a procedure. 

For if we remove up to the fourth rib, the scapula will revolve on
a frontal axis corresponding to the projecting fourth rib, and a frontal axis corresponding to the projecting fourth rib, and
thereby the angle of the scapula will be drawn in towards the thoracic cavity. But that depression would be very incomplete, and it is not until the fourth, third, and second ribs have been removed that the scapula in its entirety can be made to fall forwards towards the thoracic cavity. This applies especially to the
posterior edge of the scapula, which cannot fall in until all the ribs posterior edge of the scapula, which cannot fall in until all the ribs against which the scapula lies, the second to the seventh and eighth,
have been resected. I did not at first resect the first rib, but of late I have been resected. I did not at first resect the first rib, but of late I
have done so 15 times, and agree with the majority of surgeons have done so 15 times, and agree with the majority of surgeons
that as a rule this should be done. In cases where there are that as a rule this should be done. In cases where there are the top, good results can be obtained without going farther than to the second rib inclusive. Amongst 15 patients whom I regard as cured in 8 cases the first rib was removed, in 6 cases up to and includi gs the second, and in one only up to and including the third rib. The last case in particular is striking, as the patient in question had a cavity of the apex, and yet has been free from can well be achieved without resecting the first rib, but give no proof as to whether I might have achieved even more cures if the proof as to whether I might have
first rib had been resected oftener.

\section{Technique Employed by the Author.}

Position of patient. - I have employed Sanerbruch's method. The patient is laid on the healthy side with a flat pillow under him, hips and knees bent at right angles, with a pillow firmly fixed to support the back of the thighs; the trunk elevated at an angle of $30^{\circ}-40^{\circ}$

Anasthetic. - In my first operation I employed paravertebral anæsthesia, and thereby secured ideal effects in spite of the fact that the patient was corpulent. In succeeding operations the effect was not so good, and I have therefore adopted the use of a local anæsthetic of the soft parts by $\frac{1}{2}$ per cent. novocaine, and when the latter have been drawn aside regional anæsthesia of each intercostal nerve with 1 per cent. novocaine.

In doing so it must be remembered that the intercostal nerve behind the angles of the ribs does not lie quite beneath the
edge of the rib, but in the intercostal space between the external intercostal muscles on one side and the endothoracic fascia and the costal pleura on the other; for the internal intercostal museles only begin at the angle of the rib. For the above anæsthesia 200 to $300 \mathrm{cccm}$. $\frac{1}{3}$ per cent. and $50-75 \mathrm{cccm}$. 1 per cent. novocaine may be used. Each patient receives in addition $0.01 \mathrm{~g}$. morphine subcutaneously one hour before, and, as a rule, another 1 egr. a quarter of an hour before the operation. In pain to the patient, although in some few cases, when the patients were more nervous than usual, the effect was not ideal; yet even in the latter cases it was possible to perform the operation without narcosis. In particular, pain is produced when we draw the front part of the rib backwards in order to get it resected far forwards. Even when the local anæsthetic works this yart of the operation.

On the day of the operation the patient must cough as much as he can in the morning so as to clear the lungs of expectoration, so that there is no risk during the operation of an attack of coughings comings on, which conld be dangerous by aspiration of sputum in one lung or the other. The position during operation renders expectoration difficult.

Incision.-This commences, when operating in one stage, at the height of the spine of the scapula, about midway between the margin of the scapula and the spinous processes. If it is desired to remove the second rib it may be necessary to go a little higher up. However, the levator anguli scapulæ may very well be kept. The incision is continued parallel to the spinous processes to the tenth rib and then bends outwards along the tenth or eleventh rib to the scapular line or a little farther. As the arm is drawn outwards and upwards, after cutting through the musculature, one can get right in under the scapula, and with the aid of broad retractors lift it away from the thoracic wall; there is then no difficulty connected with resection of as large pieces of rib as we wish. Resection begins from below, and not until the seventh or eighth rib is reached does the

manouvre with the scapula becolne necessar

It is not always easy to say whether the rib before one is the tenth or the eleventh, but $I$ am not alone in being unable to count up to 11 in these circumstances, and must recommend that attention be directed to this point. As a rule, one does not locate the eleventh rib low enough, taking the tenth in the belief that it is the eleventh, until the error is discovered higher up, or it may be only when one has the Rontgen photograph as a guide. On one occasion I made a mistake in counting, because it appeared that a cadaver had not more than 11 ribs on either side. The twelfth was quite rudimentary and not more than $1-3 \mathrm{~cm}$. long.

Through the above incision I have removed as much as $183 \mathrm{~cm}$. of nine ribs in all; in one case $150-160 \mathrm{~cm}$. Friedrich, through the Schede incision, which is far more mutilating for the musculature, removed 130-160 $\mathrm{cm}$.; as far as concerns facility for removing ribs, Sauerbruch's curved incision is not inferior to the other. I have already expressed my doubts as to whether such a huge resection is really necessary at any time. One must aim at getting as far behind the ribs as possible-i.e., to the point of the transverse processes.
After resection of the ribs yellowish-white nodules can, as a rule, be seen through the costal pleura, and by palpation hard nodules in the lung tissue can readily be felt, the size of a grain and upwards to the size of a nut. The pleura is more or less thickened, but by no means so much so as we are accustomed to see in old empyemata. The musculature is sewn together with catgut, the skin with silk.

I have performed the operation in some cases with one, and in others with two assistants. As a rule it lasted one hour. Technically it is considerably easier in women than men, as the ribs are much thinner in the former, and the periosteum and musculature are much more easily separated from the ribs. This is especially noticeable in the posterior part of the ribs, where the iliocostal and longissimus dorsi muscles, and also the deep short rib muscles, have their origin or insertion.

Resection of the two upper ribs.-This is not always simple, especially when dealing with the first rib. This part of the operation can be considerably facilitated if, after resection of the fourth or third rib, we carefully cut through the periosteum and the endothoracic fascia, and then undertake a loosening of the apex of the lung, or regular apicolysis. The lung is thus removed from the ribs, and therefore no risk is run of its lesion during resection of the second and first ribs; in addition the apicolysis contributes per se towards further collapse of the lung.

Drainage. - Since the Gothenburg Congress in 1916 I have followed Dr. Key's example: a glass drain 8-10 cm. long is placed in the posterior angle of the incision, and removed on the first or second day after the operation. In this manner healing undoubtedly proceeds more easily and surely than with the tamponade previously employed by me.

My ten first cases were all operated on in one stage, but from the eleventh all are operated on in two stages, with an interval of seldom more than 2-4 weeks between the first and second stage.

I always have performed the first stage under local anæsthesia, and I then usually resect from the eleventh to the sixth, or, rather, fifth rib; in the second stage the remaining ribs, ineluding the first, are resected. In the last year I have several times performed the second stage under nareosis (ether-chloroform, $3: \mathrm{J}$ ), partly because many patients are very nervous of the second stage, partly because local anæsthesia is more difficult to establish in the upper part of the chest. When dealing with a large cavity in the apex I hesitate to use general narcosis, fearing lest the contents of the cavity be pressed into the bronchi, from which

Intrathoracic transplantation of fat.-Those who have performed these operations will know that cavities in the apex give the greatest difficulty in achieving an entirely satisfactory result. In these cases the momentary effect of thoracoplasty is often strikingly good, but sooner or later profuse expectoration and subfebrile periods may again appear, and the physical signs of a cavity again become more pronounced. Three years ago I drew attention to Tuffier's intrathoracic fat transplantation as a method which in these circumstances should be employed. Since January, 1917, I have employed transplantation of fat in nine patients, in order to cause an obstinate cavity to collapse. I have resected a rib, made an apicolysis and placed fat in the cavity formed between the thoracic wall and the surface of the lung. After having experimented with slightly varying modifications I decided upon the following method.

Patient on back. Pillow under shoulder. Begin at axilla with a longitudinal incision, the lower end of which bends forward, $10-15 \mathrm{~cm}$. in length. The edges of the incision are drawn far apartand I then resect 6-8 $\mathrm{cm}$. of the third or fourth rib, whereby we usually meet with the foremost resection incision from the previous operation. From my experience the second rib should not be selected, as its situation is too difficult from the axilla onwards. One cuts carefully through the periosteum and endothoracic fascia, thus reaching the correct layer for apicolysis-viz, between the parietal pleura and the endothoracic fascia. If we should happen to work in between the two layers of the pleura, this would scarcely be of any practical importance. The danger of opening tuberculous foci is, perhaps, a little greater. It is easiest to loosen first from the lower edge of the wound, and then no farther down than one to two fingers' breadth. Begin to loosen cautiously with a Kocher's probe or some other blunt instrument, later with a finger wrapped in gauze. If in the right layer, the loosening of the apex itself proceeds very easily. Continue to loosen as far upwards as to the first rib and one has then made a cavity the size of a hen's egg or a medium-sized potato. The cavity can be enlarged without difficulty, but it is not advisable, as it is hard to procure a pateh of fat 
thick. There is no bleeding worth mentioning, but in order to stop all oozing tampon

The fat.-This is best taken from the abdomen by means of a large arc-shaped incision with the convex side outwards. The skin with a quite thin layer of fat is dissected aside to a large extent, so that one can remove the subcutaneous fat with superficial fascia in one connected piece. The size of the piece depends partly upon that of the cavity we have to fill, partly apon the adiposity of the individual. If the latter is only slight, the area of the piece must be made correspondingly greater. In general, the size of the piece varies from that of the palm to that of the entire hand. The fat is kept in a sterile dry compress, whereupon the wound in the abdomen is sewn up with a glass drain at each corner. The fat can also be applied at once to the thorax and the sewing up of the abdomen be postponed until later.

The wound in the axilla is again laid bare, the tampon in the cavity removed, the edges of the wound of the periosteum drawn well away from each other by retractors and the piece of fat pushed into the cavity by means of forceps, and aided by Kocher's spoon. into the cavity by means of forceps, and aided by Kocher's spoon. It does not easily slip out again as it finds support against the thoracic wall both above and below the opening of the wound. One endeavours as far as possible to smooth out the piece of fat inside
the cavity so that it does not lie like a rolled-up lump, but falls naturally against the walls of the cavity. If the piece is thin it may naturally against the walls of the cavity. If the piece is thin it may be necessary to fold it double. In that case I prefer to allow the superficial fascia to turn outwards so that it comes in contact with outside the lung. The wound is then completely closed in three layers without drainase; first the periosteum with catgut, then layers without drainase; first the periosteum with catgut, then well compressed bandage is applied to support the wound durin well compressed band

In selecting the axilla as the point of entrance instead of the anterior surface of the thorax my reason was first and foremost because a complete apicolysis is far more easily achieved from the axilla.

From the anterior surface it is very difficult to get quite over to the back of the apex of the lung. Moreover, the scar in the axilla is practically invisible. If primary healing does not occur drainage
is more successfully carried out at the axilla than in front. Apart from the apicolysis the technique is easier by an anterior incision, and probably asepsis is also more certain, as, of course, perspiration often collects in the axilla. I now have the patient shaved the day before the operation, washed carefully, and left with a $\frac{1}{2}$ per cent formalin compress throughout the night.

The cough sometimes results in the abdominal wound troubling the patient a good deal. In order to avoid this I have in some cases taken the fat from the outside of the thigh; but this fat has a different character from the subcutaneous abdominal fat, being considerably firmer and therefore adapting itself less readily to the walls of the intrathoracic cavity. For this reason I have returned to the abdomen. The transplantation of fat in these circumstances is not an ideal example of transplantation of tissue, because the transplanted substance must be intimately connected with the surrounding tissue on all sides. The cavity made between the lung and the thoracic wall being completely stiff-walled on the outer side, it is not easy for the transplanted matter to make contact everyWhere. This arawback is partiy outweighed by the circumstance that the other wall-the wus-can to some extent approach the undisturbed healing of the transplanted substance. It might be advisable in cavities in the apex to defer the transplantation of fat advisable in cavities in the apex to defer the transplantation of fat to the second stage of the thoracoplasty, apicolysis being performed
at the same time. The cavity would just after resection be at the same time. The cavity would just after resection be
surrounded by more pliant walls, making it easier for the transsurrounded by more pliant walls, making it easier for the trans-
planted tissue to come into contact with healthy tissue on all sides.

As far as the further fate of the transplanted fat is concerned Tuffier's investigations have shown that in aseptically healed cases it is converted into firm, fibro-adipose tissue.

Of the 9 intrathoracic fat transplantations which I have performed, healing has been achieved in 5 cases. I am certain, however, that this does not give a correct impression of the success of the method.

Three of the operations were unfortunately performed at a time when there was in my wards a series of infections, the cause of which could not be traced. It was particularly unfortunate that three so comparatively rare operations should have taken place just at the period of the only "hospital epidemic "I have ever experienced. A fourth case now goes about with quite a small sinus in the axilla. In the other five patients, healing took place either primarily or after a brief evacuation of viscous fluid containing a great percentage of fat. The latter must to some extent be regarded as a proof that the transplanted tissue did not entirely fill up the artificially made cavity. If the formation of a sinus should occur, the bandage should be so laid as to compress strongly, upon which the secretion in aseptic cases soon ceases. The effect of fat transplantation in four cases was splendid, cough and expectoration disappearing

Course of Disease and After-treatment.

When operating in one stage the first part of the operation, until the sixth or fifth rib is reached, usually proceeds with normal pulse and respiration, but during the resection of the upper ribs both often increase considerably in frequency; the pulse may rise to $140-160$ and the respiration to about 40 . Shortly after the operation, and sometimes before its completion, the pulse often goes down to $110-120$ and the respirations to 20-30. In some cases the pulse did not exceed 80-90 and the respirations $28-30$, in spite of a large resection. Some patients suffered from nausea and vomited during the operation, which I consider to be the effect of the morphine and novocaine. At the conclusion of the operation nearly all the patients could sit upright on the operating table whilst the bandages were possib applied. Even just after the conclusion of the operation it is nexion with "a considerable sinking in of the thorax wall in con drawn in at each inspiration and bends outwards at each expiration. Dyspncea and laboured expectoration, with pains in the breast radiating to the arm, especially trouble the patient during the first days after the operation. The dyspnoea is partly due to of dislocation. The heart must, as it were, grow accustomed to the latter before resuming its regular work. In one case in particular the dyspnœa was pronounced on account of mediastinal flutter ; pulse 130, resp. 36-40. There was considerable cyanosis and the pulse 130, resp. 36-40. There was considerable cyanosis and the more pronounced was the dyspnoea and the less favourable did the pulse become. Omnopon 002 subcutaneously had a wonderfu tion steadier, and she again fell asleep. Narcotics were not spared, and after some days the crisis was passed.

Expectoration.-Narcotics must be given during the first days. It is of the greatest importance to get the patient to cough up the sputum; pain connected with coughing must therefore be prevented. I prefer omnopon, which seems as a rule to work better than morphine.

The patient must at first have an extra nurse day and night, especially to support the affected side during attacks of coughing, and to encourage the patient. Coughing is considerably eased by support of that part of the thorax mobilised by the operation (Sauerbruch's bandage, plaster bandage) but care must be taken that the means of support employed will not compress the other half of the thorax, and thereby hinder it during respiration. The bandage also has another purpose-viz., to help press the mobilised pert of the thoracic wall in against the thoracic cavity, so that the requisite inward pressure of the thoracic wall is secured when the ibs are regenerated.

One striking feature is the influence of the operation upon the amount of sputum.

In most cases it sank even during residence in hospital from more than $150 \mathrm{c.cm}$. per 24 hours to $25-50 \mathrm{c.cm}$. In one case it entirely disappeared, and in some others almost so. Sometimes the amount of sputum entirely disappeared in the course of the two or three months following the operation. As a rule a rapid decrease in the amount of sputum is a good prognostic sign, yet not always. In one of my cases after resection of the eleventh to fifth ribs there was a rapid and considerable decrease in the amount of sputum, from $90 \mathrm{c.cm}$. to $6 \mathrm{c.cm}$. in the course of four weeks, and for that reason I refrained from resecting the other ribs. Ten months later I had to resect the fourth to second ribs, whereby the amount of sputum, that had again risen to $175 \mathrm{c.cm}$., sank to $10-15 \mathrm{c.cm}$. Yet even in lung in which there was a cavity. The patient refused furthe operations, and a few days after departure had a fatal hæmoptysis. Yet even in cases where the final result is unsatisfactory the operation often effects a temporary reduction in the amount of sputum. Even when the amount of sputum rapidly decreases-i.e., in the within of two to four weeks-the decrease is irregular, so that ony the amount of sputum diminishes the tubercle bacilli in the expectoration also disappear. This was the case with nearly onehalf of my patients, in one case as early as seven weeks after the operation. Simultaneously with decrease in expectoration the cough naturally, wholly or partially, disappears, this being the point most appreciated by the patient.

Temperature, pulse, and pain.-In the succeeding days there is often a rise in temperature, in favour able cases somewhat moderate, $37^{\circ} 4^{\circ}-38^{\circ} 5^{\circ} \mathrm{C}$, lasting not more than $4-5$ days. The pulse rises relatively more and remains at 110 to $120-130$ for several days. In other cases the temperature may rise above $39^{\circ}$, the pulse to $130-140$, and yet primary healing of the wound may take place. In these cases both rise in temperature and high frequency of pulse are a result of pulmonary complications. High temperature up to $40^{\circ}$ or above, and frequency of pulse 120-140, which show no signs of descending in the following days, give an unsatisfactory prognosis.

I have already mentioned that during the first few days the patient often complains of severe pains in the operated half of the thorax, pains which of ten radiate to the arm and down to about the elbow. These pains usually decrease considerably shortly afterwards, but may continue, even if less intense, for weeks and even months. After the lapse of a few days the patient usually feels better, and the large wound grows together surprisingly quickly, so that he can often get up after two to three weeks, and can be sent away for continued sanatorium treatment after four to six weeks.
In some cases the reaction after the one-stage operation is great: 
after my tenth case I preferred to carry out the operation in two stages. This division entails the disadvantage of the patient's vivid recollection of the first operation when he to submit to it. I hasten to add that I have never met with a to submis.

But in favourable cases the patient recovers quickly after the operation, appetite and weight increase, temperature falls to the normal, cough diminishes, and his improved subjective condition puts him in better spirits. Some patients even have a decided conviction that the disease has released its hold on them.

The operated side of the thorax falls in considerably, so that the edge of the scaplala is visible from in front. With the aid of the cyrtometer a decrease in the circurnference of the operated side of 5-6 cm. or even more can be demonstrated. In several of my patients it has been found that the diminution in chest measurement the xiphoid process. We can distinctly feel how the anterior ends of the resected ribs approach the posapproach the posterior ends, so that the distance between them diminishes from 12-15 cri. to 5-6 or 3-4 and even less. At the same time, the foremost extends downwards, so that, for instance, the anterior end of the seventh rib is opposite the posterior end of the eighth. With women the breast slips to the side and the nipple often points at an angle of $45^{\circ}$ (the sagittal plane), whilst otherwise it on $1 \mathrm{y}$ deviates $10-15^{\circ}$ outwards from it. In the course of time scoliosis in the corresponding part of the spinal column develops; this scoliosis is the reverse of that found in empyemata, the convexity being towards the diseased side, presumably because in operating large or small portions

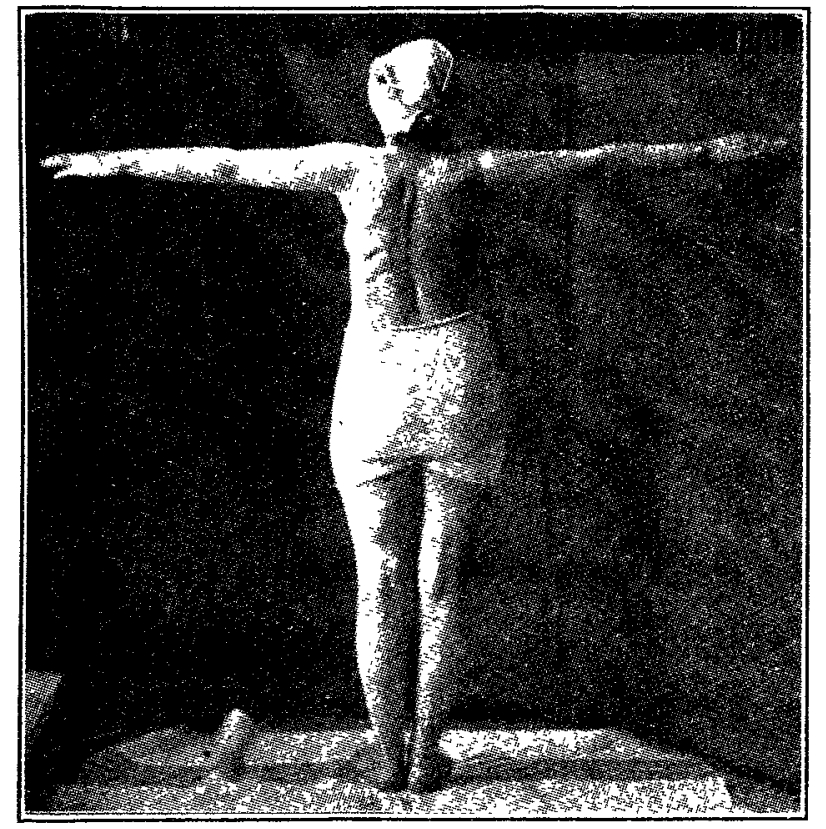

Showing the result of thoracoplasty in a female patient, 19 years old, after the second operation. Note the diminution in volume of the left half of the thorax, of the arm.

of the back are cut or paralysed, so that the muscles of the other side draw the spinal column over. The mobility of the arm is at first restricted on account of pain, but it returns by degrees unless said that the lasting inconveniences are small.

Signs Indicative of Success of Operation and Progress of Cure.

Complications in the opposite lung or other organs may render difficult an estimation of the effectiveness of the operation. But in addition to the usual clinical symptoms, pulse, temperature, amount of sputum, disappearance or persistence of tubercle bacilli, physical condition of the lung, and general condition, Rontgen pictures will be of great importance in enabling changes in the lung, especially the condition of cavities, to be followed.

Not one symptom only, but the entire aspect of the case, must be taken into consideration. I have mentioned that the amount of sputum may temporarily disappear almost entirely after the operation, but that this disappearance does not necessarily mean that a cure has taken place. Estimation of the physical signs may be very difficult after the operation. If before the operation there were more or less distinct signs of a cavity, it will be found in favourable cases that the moist sounds or bronchial breathing are by degrees replaced by crepitations But all abnormal sounds do not disappear, and amphoric breathing,
presumably produced by the larger bronchi, may continue presumably produced by the larger bronchi, may continue permanently or for a long time. Even in the most fortunate cases normal conditions in the lung will of course never be recovered. The percussion sound will remain flat and at certain
places slightly tympanitic, at points almost dull; the respiratory places slightly tympanitic, at points almost dull; the respiratory
naurmux will be rough or tubular on account of the large uncollapsed bronchi that run through collapsed pulmonary tissue, and may be heard more or less extensively, because both the lung itself and the thoracic wall have lost their elasticity, thus more or less preventing the lung from being rid of sputum. Scanty mentioned physical changes can therefore not be regarded as of mentioned physical changes can therefore not be regarded as of any importance, as soon as general conditio operating.

\section{Discussion of the Indications.}

The first case was referred to me by Dr. W. Holmboe, chief physician at Mesnalien Sanatorium for Pulmonary T'uberculosis; he therefore has the honour of being the first in Norway to give indications for the operation of these patients. All the following patients have also been referred to me by the physician treating them at their respective hospitals or sanatoriums.

No doubt it is agreed that there can only be a question operating in a case of unilateral pulmonary tuberculosis, or remains practically stationary for a lons time. In both cases the patient's general condition is reduced by fever or constant coughing, with more or less abundant expectoration. It is then important to operate before the patient is too much reduced by the disease. As the effect of extrapleural thoracoplasty may be compared with the effect of treatruent by pneumothorax, both prothora, $x$ oth pro-
ducing collapse of
the diseased lung, and as further inflation must be regarded as considerably less dangerous, I have generally demanded that pneumothorax treat ment shall have been attempted without result, or that it was account of extensive pleural adhesions.

Thus, on the whole, it may be said that indica. tions for extrapleural thoracoplasty coincide with indications for artificial pneumothorax treatment, and that the former is utilised when the latter cannot be carried out. The extent of the infection in the diseased lung must have reached a certain stage before so serious an operation should be under taken. An advanced destructive process with the formation of cavities inclines one to intervene earlier than when the tuberculosis, assuming a more fibrous form with shrinkage, runs a chronic course.

Condition of the other lung.-The requirement that the other lung must be healthy must not be understood to mean that in the event of post-mortem examination no tuberculosis would be found in it.

So strict a demand would mean few operations. By "healthy" in these cases is meant that either no affection in that lung is, or has been, clinically demonstrable, or even though at one time there was some affection it has disappeared. It, however, is more difficult to judge those cases, which perhaps are most frequent, where insignificant changes can be demonstrated in the better lung. In one of my cases which resulted in death we were unable to find any definite signs of disease in the "healthy" lung just before the operation, and yet a cavity the size of a nut was subsequently found in the upper lobe. Some of my patients showed no clinical signs that the other lung was attacked.

\section{Other Symptoms and Contra-indications.}

There may also be other symptoms to consider in deciding whether to operate or continue expectant treatment. I have here specially in mind repeated hæemoptyses, and also, perhaps, shrinkage, with marked dislocation of heart and trachea, as factors in favour of

Contra-indications for operating are advanced disease in the other lung or tuberculosis in the lower lobe of the other lung, also other localisations of tuberculosis (kidneys, intestines, bones, joints, \&c.) in addition to the usual contra-indications that hold good for all large operations. A slight laryngeal tuberculosis has not kept me from operating, as I considered that an eventual improvement in the pulmonary tuberculosis, with decrease of cough and sputum, would exercise a beneficial influence
on the laryngeal tuberculosis, almost like that of the improveon the laryngeal tuberculosis, almost like that of the improvemidney. 
In order to decide the various factors which I have here inentioned it is absolutely necessary for the patient to be for a considerable time under the observation and treatment of a competent physician. The latter alone can decide whether the disease is stationary or progressive. He is best qualified to predict the restut of contintued expectant treatinent, so far as that is feasible in pulmonary tuberculosis. On the , other hand, the surgeon must not perform operations to order. Because even though pulmonary diseases, and especially pulmonary tuberculosis, do not, as a rule, fall within onr special province, the surgeon must use his common sense when deciding whether the patent can bear the and arrangernent of the operation.

\section{Results.}

From May 1st, 1914, to June, 1919, I performed 37 extra-pleural thoracoplastic operations in pulmonary tuberculosis; in the last year I have performed a further 11. Of my first series of 11 patients 3 died immediately after the operation; of $\mathrm{my}$ socond series of 26 patients only 1 died. The immediate mortality was thus reduced from about 30 per cent. to 4 per cent., or for all the cases to about 10 per cent. I ascribe this extremely remarkable improvement in the statistics principally to the performance of the operation in two stages. 1 As regards the four deaths, three of them were undoubtedly due to infection. Clinically it was remarkable that in spite of the high temperature there was a clean and moist tongue the whole time.

The immediate and lasting results of my operations will appear from the following table :-

Results of Operations (37 Cases).

\begin{tabular}{|c|c|c|c|c|c|c|c|c|}
\hline \multirow{2}{*}{ Years. } & \multirow{2}{*}{ No. } & \multirow{2}{*}{ Men. } & \multirow{2}{*}{ Women. } & \multirow{2}{*}{$\begin{array}{l}\text { Died } \\
\text { after } \\
\text { opera- } \\
\text { tion. }\end{array}$} & \multicolumn{2}{|c|}{ Living. } & \multicolumn{2}{|c|}{ Died later. } \\
\hline & & & & & $\begin{array}{l}\text { Able to } \\
\text { work.* }\end{array}$ & $\begin{array}{l}\text { Tuber } \\
\text { culous }\end{array}$ & $\begin{array}{l}\text { Of pul. } \\
\text { tuberc. }\end{array}$ & $\begin{array}{l}\text { Oth } \\
\text { caus }\end{array}$ \\
\hline & $\begin{array}{l}5 \\
4\end{array}$ & $\frac{1}{2}$ & $\begin{array}{l}4 \\
2\end{array}$ & $\overline{2}$ & 2 & I & $\begin{array}{l}3 \\
2\end{array}$ & 二 \\
\hline & 4 & 1 & 3 & 1 & - & 2 & 1 & 二 \\
\hline & 14 & 3 & 11 & 1 & 7 & 4 & 1 & 11 \\
\hline 1919 & $\begin{array}{l}6 \\
4\end{array}$ & $\begin{array}{l}4 \\
1\end{array}$ & 3 & - & 3 & 1 & 0 & E \\
\hline tal. & 37 & 12 & 25 & 4 & 15 & 10 & 7 & 1 \\
\hline
\end{tabular}

*Free from symptoms. † Influenza-pneumonia.

Seven patients died subsequently of their tuberculosis, one nearly our years after the operation. One died of influenza-pneumonia one year after the operation. It is doubtful whether her tuberculosis had been cured. Thent 15 may be considered as cured, they are entirely, or practically, ht for work, always afebrile, and tubercle bacilli can no longer be demonstrated in the sputum. They have no daily cough, but some of them, as might reasonably be expected, are more liable to temporary colds than other people. Ten live, with symptoms of their pulmonary tuberculosis.

So far, then, I have obtained a curative result of tuberculosis in 15 of the 33 patients-i.e., about 45 per cent. of those who survived the oceration, or 40 per cent. of the total number operated on. Time will show if this calculation is too optimistic. I take it to be a good sign, however, that two of the 1914 patients are still well. Amongst the patients there are several who cycle-against my advice-and one has hard manual labour for as many as ten hours a day. Two women and one man have married. One of the women, exactly one year after the operation, gave birth to a child, which weighed $4 \mathrm{~kg}$., and 15 months later gave birth to a second. She scrubs her floor, does all her own housework, and feels quite well.

\section{Conclusions.}

A critical study of the 18 cases which were not so satisfactory leads me to the following conclusions:In 3 cases the operation was incomplete; in 2 because at first I lacked sufficient experience, and in the third because the patient's general condition before the operation was so poor that he could not bear it, and it therefore had to be interrupted and left incomplete. It may be fitting to observe here that extrapleural thoracoplasty is too large an operation to be made consolationis causâ. If there are no reasonable chances of a good result one should refrain from operating, as to do so can only tend to make the operation unpopular with medical

${ }^{1}$ Of the last 11 patients one died immediately. men and public alike. All the three patients with incompleted operation subsequently died of tuberculosis. One patient died of influenza-pneumonia; she, however, was hardly cured of her pulmonary tuberculosis. In 10 cases the other lung became diseased, in one case after influenza, which is to be blamed for aggravation of the complaint in several other instances, to some extent with hæmoptyses. Four patients had a temporary improvement, but nevertheless do not recover satisfactorily in spite of the fact that the other lung still appears to be healthy. Coughing and expectoration persist, in some cases with tubercle bacilli, in others without. Two of these patients have also suffered from nephritis. In one case the result was better after transplantation of fat and treatment at a sanatorium. The sword of Damocles that overhangs the patient is the danger that the other lung may become diseased. We cannot expect to obviate this danger, and it can only be reduced by a lengthy stay at a sanatorium after the operation, and careful choice of occupation later. Sport and hard work should bé forbidden for life, even in the best cases. On the other hand, it is not always clear why certain patients do not recover entirely in spite of good technique, and in spite of the fact that the other lung is not involved. It is possible that this may be connected with thickening of the pleura which prevents the lung from collapsing sufficiently. Future observation may perhaps solve this problem for us. I believe that by improvements in technique and greater practice in prognosis early in the disease, so that cases suitable for operation come for surgical treatment at an earlier stage, better results will become possible.

The results that I have given are to a great extent due to the friendly coöperation of various sanatorium physicians, who from the beginning showed an understanding of the importance of extrapleural thoracoplasty. But frequently, when I have talked to other colleagues about thoracoplasty and pulmonary tuberculosis, I have been met with the objection that the operation is too dangerous and that the speaker has "no faith in it." One should always listen to expert criticism, but it has been found that the views mentioned above are based upon lack of personal experience and upon ignorance of what has been achieved. Against this negative criticism I desire to make a protest by the publication of my results. I can confidently assert that those patients who are well are all most grateful. It must be remembered that they are people who in many cases have been ill for a long time, having in some instances gone from one physician to another or from one sanatorium to another, and having little by little come to the conclusion that nothing can cure them. After an operation attempted as a last resort they feel that the power of the disease is broken, and the ability to enjoy life has returned. Their gratitude is therefore not difficult to understand.

\section{Summary.}

My experience of extrapleural thoracoplasty in pulmonary tuberculosis may be summarised as follows :-

1. In unilateral, or mainly unilateral pulmonary tuberculosis, which is not cured by rational treatment (including pneumothorax), good results can be achieved by means of extrapleural thoracoplasty.

2 . The operation should only be performed after conference with the physician treating the patient, who must have had an opportunity, by observation during a considerable period, of forming a thorough opinion of the prognosis in the case concerned.

3. Resection of the ribs should be carried out under local anæsthesia through a paravertebral incision, so that the posterior part of the ribs from the eleventh, or, in any case, from the tenth to the first inclasive, can be removed.

4. If a cavity remains, it can be brought to collapse by means of intrathoracic transplantation of fat.

5. It is necessary that practising physicians should acquire knowledge of the indications and results of extrapleural thoracoplasty. One has now no right to withhold the chance of operation from suitable patients. 